\title{
The potential role of phytochemicals in wholegrain cereals for the prevention of type-2 diabetes
}

\author{
Damien P Belobrajdic ${ }^{1,2^{*}}$ and Anthony R Bird ${ }^{1,2}$
}

\begin{abstract}
Diets high in wholegrains are associated with a 20-30\% reduction in risk of developing type-2 diabetes (T2D), which is attributed to a variety of wholegrain components, notably dietary fibre, vitamins, minerals and phytochemicals. Most phytochemicals function as antioxidants in vitro and have the potential to mitigate oxidative stress and inflammation which are implicated in the pathogenesis of T2D. In this review we compare the content and bioavailability of phytochemicals in wheat, barley, rice, rye and oat varieties and critically evaluate the evidence for wholegrain cereals and cereal fractions increasing plasma phytochemical concentrations and reducing oxidative stress and inflammation in humans. Phytochemical content varies considerably within and among the major cereal varieties. Differences in genetics and agro-climatic conditions explain much of the variation. For a number of the major phytochemicals, such as phenolics and flavanoids, their content in grains may be high but because these compounds are tightly bound to the cell wall matrix, their bioavailability is often limited. Clinical trials show that postprandial plasma phenolic concentrations are increased after consumption of wholegrain wheat or wheat bran however the magnitude of the response is usually modest and transient. Whether this is sufficient to bolster antioxidant defences and translates into improved health outcomes is still uncertain. Increased phytochemical bioavailability may be achieved through bio-processing of grains but the improvements so far are small and have not yet led to changes in clinical or physiological markers associated with reduced risk of T2D. Furthermore, the effect of wholegrain cereals and cereal fractions on biomarkers of oxidative stress or strengthening antioxidant defence in healthy individuals is generally small or nonexistent, whereas biomarkers of systemic inflammation tend to be reduced in people consuming high intakes of wholegrains. Future dietary intervention studies seeking to establish a direct role of phytochemicals in mediating the metabolic health benefits of wholegrains, and their potential for mitigating disease progression, should consider using varieties that deliver the highest possible levels of bioavailable phytochemicals in the context of whole foods and diets. Both postprandial and prolonged responses in systemic phytochemical concentrations and markers of inflammation and oxidative stress should be assessed along with changes related to health outcomes in healthy individuals as well as those with metabolic disease.
\end{abstract}

Keywords: Wholegrain, Phytochemical, Type-2 diabetes, Oxidative stress, Inflammation

\footnotetext{
* Correspondence: damien.belobrajdic@csiro.au

${ }^{1}$ Commonwealth Scientific \& Industrial Research Organisation (CSIRO) Food

Futures National Flagship, GPO BOX 10041, Adelaide, SA 5000, Australia

${ }^{2}$ CSIRO Animal Food \& Health Sciences, Adelaide, SA 5000, Australia
} 


\section{Metabolic disease and protective role for wholegrains}

Type-2 diabetes (T2D) is a major health problem worldwide. Rates are increasing alarmingly in many countries and the global incidence is predicted to rise from 366 million people to about 552 million in the next two decades $[1,2]$. It is a leading cause of death and disability globally and carries a considerable socioeconomic burden, especially in low and middle income settings [2-5]. Cost-effective mitigation strategies rather than containment are therefore of paramount importance. The initiation and progression of $\mathrm{T} 2 \mathrm{D}$ and related chronic metabolic disorders is governed by a complex interplay of genetic and multiple lifestyle influences of which diet is a major and modifiable high exposure risk factor. Dietary change has proven successful in both preventing and managing diabetes and, when combined with other lifestyle modifications, such as regular exercise and weight loss, is more effective than pharmacological interventions [6].

Dietary patterns featuring wholegrain cereals are associated with reduced risk of T2D [7-10]. Systematic reviews and meta-analyses of large, prospective studies consistently demonstrate that frequent consumption of wholegrain foods improves metabolic homeostasis and delays or prevents the development of T2D and its complications in a variety of cohorts, albeit mostly of European ancestry [11-18]. Two to three serves daily of wholegrain foods reduced the risk of T2D by $20-30 \%$ compared to about 1 serve a week [12,13,15,18]. Randomised, controlled dietary studies in humans and other experimental research provides evidence of a causal relationship between wholegrain consumption and diabetes prevention $[15,18]$. Furthermore, wholegrain foods improve indices of diabetes risk, including glycemic control, fasting plasma insulin and glucose, and insulin sensitivity and also aid in the management of those individuals with or at high risk of developing T2D [13,16,19-21].

\section{Mechanisms by which wholegrains might protect against type-2 diabetes}

Understanding the mechanisms by which wholegrains prevent or delay the onset and progression of T2D is pivotal to developing effective diabetes prevention options. The components of wholegrains which are responsible for protecting against diabetes have not been clearly identified but the high nutrient and fibre contents in general, as well as the physical structure of wholegrains are considered leading contenders [15,22,23]. Prospective studies show that T2D risk is inversely related to cereal fibre intake [18] and that cereal fibre accounts for much of the reduction in diabetes risk associated with wholegrain intake [24]. Dietary fibre is concentrated primarily in the bran layer of grains and it is this fraction which is more strongly associated with reduction in risk of T2D [17]. Most but not all wholegrains are high in fibre [25] and individual wholegrains differ markedly in the types and hence physiological properties of fibres they contain. Viscous soluble fibres, such as those in oats and barley, slow available carbohydrate assimilation and dampen postprandial glycemic and insulinemic responses [26]. However most observational studies provide evidence of a protective role for insoluble rather than soluble fibres [27]. The likely explanation is that insoluble fibre is simply serving as a marker of an intact (grain) food structure. Foods and diets rich in carbohydrates that are rapidly digested and absorbed have adverse consequences for metabolic health [28-33]. Refinement of cereal grains removes the protective bran layer and greatly increases starch availability. However, not all wholegrain foods elicit a moderate glycemic response [34]. Although wholegrain foods may contain intact, cracked, broken or flaked kernels, most commercially processed cereal foods consist of ground and reconstituted wholegrain products [25].

Wholegrains contain a plethora of minerals, vitamins and phytochemicals [35] and it is often difficult to ascribe protective effects on metabolic health to any one particular constituent, such as fibre. One of the primary pathogenic factors leading to insulin resistance, $\beta$-cell dysfunction, impaired glucose tolerance and ultimately T2D is oxidative stress [36-38]. This mechanism has been implicated as the underlying cause of both the macrovascular and microvascular complications associated with T2D [39]. Furthermore, the cells and tissues of people with metabolic syndrome and T2D have an impaired ability to cope with the burden of increased oxidative stress [40-42]. Therefore, dietary components including phytochemicals (non-nutritive, plant bio actives that reduce risk of chronic diseases [25]), and a limited number of micronutrients that function as antioxidants, may prevent the development and progression of metabolic syndrome and T2D by reducing oxidative stress [35]. Furthermore, systemic, low grade inflammation, especially in adipose tissue, is a hallmark of many chronic diseases, including T2D [43]. In addition to their antioxidant properties, some cereal phytochemicals have potent anti-inflammatory actions $[44,45]$ and may thereby modulate diabetes risk by this mechanism as well $[43,46,47]$.

\section{Phytochemicals in whole grains}

Wholegrains generally contain diverse combinations of phytochemicals depending on the type of cereal, location within the grain and how the grain has been processed. The outer structures of grains, in particular the pericarp seed coat and aleurone layers, contain much higher levels of phytochemicals such as phenolic compounds, phytosterols, tocols, betaine and folate, than the germ 
and endosperm [48]. Phenolic compounds are the most diverse and complex class of phytochemicals in cereal grains $[35,49]$. They include numerous derivatives of benzoic and cinnamic acids as well as flavonoids, flavones and flavanols, anthocyanidins, avenanthramides, lignans and alkylresorcinols. In most grains phenolic acids are concentrated in the bran and embryo cell walls and exist mostly in an insoluble bound form, free and soluble-conjugated forms being minor entities $[25,48]$. The phenolic acid content of wholegrains is considered a major contributor to total antioxidant capacity [25]. Other major phytochemicals that occur in wholegrains which may have a role in protecting against diabetes include various carotenoids, notably $\alpha$ - and $\beta$-carotene, lutein, $\beta$-cryptoxanthin and zeaxanthin, all of which are located mainly in the bran and germ fractions [49]. Aside from some having pro-vitamin A activity, they all function as antioxidants. Other phytochemicals with strong antioxidant capacities include phytate (which chelates prooxidant minerals) and various terpenes and terpenoids (phytosterols and tocols).

To render them palatable, grains are processed by various means including milling, grinding and flaking. Although these treatments may reduce content of phytochemicals, their bioavailability is often increased $[45,50,51]$. Thermal and bioprocessing too can improve phytochemical bioavailability, especially the latter method, although the results are not always consistent.

Differences among the most economically important cereals in their contents of various micronutrients and phytochemicals are shown in Table 1 . Note that the phytochemical values refer to uncooked wholegrains. Wholegrains are normally cooked and are rarely consumed in their unprocessed or raw form. Cooking results in considerable reductions in their phytochemical levels. For instance, quick-cooking wild rice had a much lower total phenolic content (2076 mg ferulic acid equivalent $(\mathrm{FAE}) / \mathrm{kg}$ ) than uncooked wild rice varieties (2472 to $4072 \mathrm{mg} \mathrm{FAE} / \mathrm{kg}$ ) [52].

\section{Variation in grain phytochemical content}

Wheat, barley, rice, rye and oats vary markedly in the types and amounts of phytochemicals they contain.

a. Wheat

The antioxidant properties of wheat have been attributed primarily to the high phenolic content, principally alkylresorcinols and hydroxycinnamic acids (ferulic, sinapic, and $\rho$-coumaric acids) that are concentrated in the bran fraction [49,75-77]. The flavonoid concentration in the bound fraction of wheat cultivars has been shown to vary from $97 \pm$ $4 \mu \mathrm{mol}$ catechin equivalents/100 g (Roane) to $139 \pm$ $17 \mu \mathrm{mol}$ catechin equivalents/100 g (Superior) [78]. However, there is less variation in total flavonoid content $(122 \pm 10 \mu \mathrm{mol}$ catechin equivalents/g (Roane) to $149 \pm 17 \mu \mathrm{mol}$ catechin equivalents/100 g (Superior) [78]) whereas tocopherols and tocotrienols levels vary more than 2 -fold ( 28 to $80 \mu \mathrm{g} / \mathrm{g}$ ) among 175 different wheat genotypes from all over the world grown at the same site in Europe [79]. Even greater variation (up to 10 -fold variation) was seen in

Table 1 The type and concentration of phytohcemicals in a range of wholegrain cereals

\begin{tabular}{|c|c|c|c|c|c|}
\hline Phytochemical & Wheat & Barley & Rice & Rye & Oat \\
\hline Methionine (g/100g) [48,53-56] & $0.17-0.24$ & $0.03-0.08$ & $0.18-0.21$ & 0.18 & 0.18 \\
\hline Cystine (g/100g) [48,53-56] & $0.19-0.40$ & $0.06-0.2$ & $0.11-0.16$ & 0.18 & 0.18 \\
\hline Selenium (mg/100g) [48,57-60] & $0.0003-3$ & $0.002-0.030$ & $0.0002-1.37$ & 0.00014 & $<0.10-3.3$ \\
\hline Folate (mg/100g) $[60,61]$ & $0.01-0.09$ & $0.5-0.8$ & 0.016 & $0.55-0.80$ & $0.05-0.06$ \\
\hline Choline (mg/100g) [48,62] & $27-195$ & $6.9-11$ & Unknown & Unknown & $2.0-2.6$ \\
\hline Tocopherols + tocotrienols [48,63-67] & $2.3-8.0$ & $4.7-6.8$ & $0.4-0.9$ & $0.4-0.7$ & $0.05-4.8$ \\
\hline Carotenoids (total) (mg gallic acid eq./100g) [48,60] & $0.04-0.63$ & $0.015-0.105$ & $0.014-0.077$ & Unknown & 0.031 \\
\hline Polyphenols (mg/100g) [60] & $70-1459$ & $50-196$ & $54-313$ & $125-255$ & $9-34$ \\
\hline Phenolic acids (total) $(\mu \mathrm{g} / \mathrm{g})[61,64,68]$ & $200-900$ & $100-550$ & Unknown & $200-1080$ & $350-874$ \\
\hline Phenolic acid (free) (ug/g) $[61,64,68]$ & $5-39$ & $5-23$ & Unknown & $10-35$ & $50-110$ \\
\hline Ferulic acid (total, mg/100g) [48,69] & $16-213$ & $110-120$ & 30 & $3.9-5.0$ & $2.1-2.4$ \\
\hline Flavanoids (total, mg/100g) [48,69] & $30-43$ & $12-18$ & Unknown & $6.7-7.5$ & $5.6-8.2$ \\
\hline \multicolumn{6}{|l|}{ Other (mg/100g) } \\
\hline Alkylresorcinols $\mu \mathrm{g} / \mathrm{g}[61,70]$ & $200-750$ & $0-150$ & Not present & $570-3220$ & Not present \\
\hline Avenanthramides (mg/100g $[71,72]$ & Not present & Not present & Not present & Not present & $4.9-27.5$ \\
\hline Betaine (mg/100g) $[48,60,62,73]$ & $22-291$ & $40-76$ & 0.5 (brown) & Unknown & $11.3-100$ \\
\hline Phytosterols (mg/100g) [48,74] & $57-98$ & $90-115$ & Unknown & Unknown & Unknown \\
\hline
\end{tabular}


$\alpha$-tocopherol levels measured in several hundred wheat cultivars grown in the United States [80].

b. Barley

The major phytochemicals in barley are phenolics, tocols and folate. Analysis of a selection of 10 barley lines showed a large variation in the concentration of total phenolics (100 to $550 \mathrm{ug} / \mathrm{g}$ ) but only minimal variation in folate (500 to $800 \mathrm{ug} / \mathrm{g}$ ) and total tocols (45 to $70 \mathrm{ug} / \mathrm{g}$ ) [61]. Our group has recently developed a new variety of barley, BARLEYmax $^{\oplus}$ [81] that has a range of substantiated nutritional and health benefits $[82,83]$. It has a phenolic content $(5 \mathrm{mg} / \mathrm{g}$ ) which is $40 \%$ greater than that of standard cultivars such as Golden Promise $(2.9 \mathrm{mg} / \mathrm{g})$ and Torrens $(3 \mathrm{mg} / \mathrm{g})$. It also contains levels of tocopherol and tocotrienols $(125 \mu \mathrm{g} / \mathrm{g})$ which are nearly 5 times those of other barley grain varieties (McInerney, JK, Morell, MK and Bird, AR unpublished data).

c. Rice

Brown rice generally is a good source of lipid-soluble antioxidants including ferulated phytosterols (i.e. $\gamma$-oryzanol), tocopherols and tocotrienols, although the levels of these phytochemicals vary widely among rice varieties [63]. For instance, tocol concentration ranged from 90 to $220 \mathrm{nmol} / \mathrm{g}$ in six varieties of rice [63]. Brown rice may also be a good source of phenolic acids as suggested by the levels reported for the botanically related wild rice (Zizaniae palustris and Zizaniae aquatica; 2472 to $4072 \mathrm{mg}$ of ferulic acid equivalent (FAE)/kg). These values are substantially higher than that of the mixed sample of white rice, basmati rice and wild rice (1460 $\mathrm{mg}$ of FAE/ $\mathrm{kg}$ ) [52]. The total phenolics content of these rices was directly related to their in vitro antioxidant capacity, which was 30 times higher for wild rice than the control (white) rice [52].

d. Rye

Rye contains more alkylresorcinols (568 to $3220 \mu \mathrm{g} / \mathrm{g}$ ) than the other major cereal varieties (0 to $750 \mu \mathrm{g} / \mathrm{g}$ ). The concentration of alkylresorcinol in rye $[70,84]$ is related to the high level of folate in the grain $(0.55$ to $0.80 \mathrm{mg} / 100 \mathrm{~g}$ ) [64]. Select varieties of rye also contain very high levels of total phenolics (up to $1080 \mu \mathrm{g} / \mathrm{g}$ ) but the content of free phenolics is quite low (between 10 to $35 \mu \mathrm{g} / \mathrm{g}$ ) [64]. Other phytochemicals, including tocols, polyphenols and ferulic acid are found at low levels in rye [64].

e. Oats

The major phytochemicals present in oats include tocopherols and tocotrienols, phenolic acids, sterols, selenium and avenanthramides (a group of $\mathrm{N}$-cinnamoylanthranilate alkaloids, unique to oats) $[85,86]$. Tocol levels differ greatly (5 to $48 \mu \mathrm{g} / \mathrm{g}$ )
$[61,65,66]$ among oat varieties but generally are comparable to those found in rice and rye ( 4 to $9 \mu \mathrm{g} / \mathrm{g})$ and also to the higher levels found in wheat and barley (23 to $80 \mu \mathrm{g} / \mathrm{g}$ ) [61]. The range in the total phenolic levels of oats are also similar to those in wheat and rye, however oats contains up to 10-fold higher levels of free and conjugated phenolics. Other phytochemicals, including folate, polyphenols, ferulic acid and flavonoids are present at low levels in oats.

\section{Major regulators of phytochemical content of cereals: genetics and agro-climatic conditions}

The phytochemical content of cereal grains is influenced considerably by genetics and a variety of agro-climatic factors. In rice, the growing environment had a greater effect on tocol and/or sterol esters of ferulic acid levels than did genotype $[87,88]$. In wheat, genetic variation and agro-climatic conditions are both important but the extent of their influence depends on the phytochemical concerned. In an assessment of over 200 lines of wheat, $\alpha$-tocopherol levels were influenced by not only varietal differences but also crop year and production site [80]. Fertilization practices, soil type and wheat variety had no influence [80]. Additionally, when eight selected winter wheat genotypes were grown under controlled conditions $\alpha$-tocopherol levels varied by as much as 3 -fold, highlighting the significant contribution of genetic variation [89]. However, studies in Europe show that tocopherol and tocotrienol levels in some wheat varieties are more susceptible to seasonal variation than others [90]. This greater susceptibility to seasonal variation and growing location is also evident in some wheat genotypes for free and conjugated phenolic levels [91]. However, bound phenolics which comprise the greatest proportion of total phenolic acids in wheat, are mostly stable across different growing conditions. Thus, the total phenolic acid content of wheat is mostly influenced by genotype, for instance winter varieties contain up to 2 -fold more total phenolic acids $(1171 \mu \mathrm{g} / \mathrm{g})$ than the average level of 175 wheat genotypes $(658 \mu \mathrm{g} / \mathrm{g})$ [92].

\section{Phytochemical bioavailability}

Bioavailability refers to the fraction of ingested phytochemical (or other dietary constituent) which reaches the systemic circulation. More commonly it is defined as the fraction which is absorbed in the gastrointestinal tract. Tracer methods, in which atoms or molecules of the phytochemical within the grain are labelled with an intrinsic radioactive or stable marker, provide the only means for accurately determining bioavailability. Given the challenges of labelling cereal phytochemicals intrinsically, this technique has not been used to measure bioavailability of phytochemicals in cereals. Simpler indirect 
measures are more commonly used, such as the balance method (intake minus fecal output), incremental area under the postprandial serum concentration curve and incremental urinary excretion. Numerous in vitro methods have also been published however they, understandably, have many limitations [93] aside from questionable validity, and so provide at best only a guide to the bioaccessibility of a phytochemical.

a. Absorption from the small intestine Bioavailability varies markedly among the different types of phytochemicals. Folate and $\alpha$-tocopherol are readily absorbed from the small intestine and their bioavailability is independent of dietary fibre content (Table 2) $[94,95]$. The majority of polyphenols however, are tightly bound to cell walls within the grain matrix thereby greatly limiting their bioavailability in the upper gut [96]. Even if polyphenols are released from the grain matrix during digestion it is unlikely that they will be absorbed in the small intestine as they are too hydrophilic to cross the epithelium by passive diffusion [97]. It is possible that there are apical membrane carriers that facilitate polyphenol absorption however the intestinal transport processes remain largely unknown [97]. Oats contain the highest levels of free, or unbound, phenolics (up to $30 \%$ of total phenolics) whereas wheat, barley and rye contain only very low levels (as little as 1.6\%) [61]. Thus specific varieties of oats have the greatest potential to raise postprandial plasma phenolic concentration and antioxidant capacity.

Wholegrain consumption elicits only minimal increases in systemic levels of phytochemicals in humans. Consumption of $100 \mathrm{~g}$ of boiled wheat bran increased postprandial plasma phenolic concentration by $5 \mu \mathrm{mol}$ ( $60 \mathrm{~min}$ post ingestion) which represented $<2 \%$ increase over baseline levels [98]. As these changes in circulating phenolic levels are minimal and of short duration it is unlikely that high intakes of wholegrains such as wheat can modulate systemic levels. Alternatively, alkylresorcinols, a class of phenolic lipids found at high levels in wheat and rye are relatively well absorbed within the small intestine (about 58\%) [99], and as they are primarily transported in the serum in lipoproteins [100] they have a half life in serum of $5 \mathrm{~h}$ [101]. However, alkylresorcinols are rather weak antioxidants per se [102] and do not affect the susceptibility of LDL to oxidation ex vivo [103]. Wholegrains wheat, oats and barley are good dietary sources of betaine which can also contribute to improving antioxidant status as well as acting possibly as a methyl donor (transmethylation) and lipotrope $[48,104,105]$. The bran and aleurone layers of wheat are concentrated sources of betaine $(\sim 1 \% \mathrm{w} / \mathrm{w})$ $[104,106]$ and there is evidence in humans that the latter source is readily bioavailable [105]. It is important to consider how components of the diet may affect phytochemical bioavailability because cereal products are rarely consumed alone. Nonheme iron when consumed with cereals reduced the absorption of phenolics [107]. Milk may also reduce the absorption of phenolics [108], however other studies have also shown no impairment [109-111]. Flavonol absorption (in particular quercetin and its metabolites) may also be affected by a variety of dietary constituents such as ethanol, fat, and emulsifiers [96], but this observation is based on evidence from in vitro and animal studies and further research in humans is required.

Table 2 Major wholegrain phytochemicals, factors affecting their bioavailability and suggested mechanisms for promoting health

\begin{tabular}{|c|c|c|c|c|}
\hline Phytochemical & $\begin{array}{l}\text { Major grain } \\
\text { sources }\end{array}$ & $\begin{array}{l}\text { Food \& dietary factors } \\
\text { affecting bioavailability }\end{array}$ & $\begin{array}{l}\text { Other factors that } \\
\text { enhance bioavailability }\end{array}$ & Potential mechanisms of action \\
\hline \multicolumn{5}{|l|}{ Phenolics } \\
\hline \multirow[t]{2}{*}{ free } & Oats & Milk & Unknown & $\begin{array}{l}\text { Increase plasma total antioxidant capacity to directly mitigate } \\
\text { oxidative stress }\end{array}$ \\
\hline & & Heme iron & Unknown & Indirect through cell signalling \\
\hline \multirow[t]{2}{*}{ bound } & $\begin{array}{l}\text { Wheat, barley, } \\
\text { oats, rye }\end{array}$ & Grain structure & Bio-processing of grain & $\begin{array}{l}\text { Increase plasma total antioxidant capacity to directly mitigate } \\
\text { oxidative stress }\end{array}$ \\
\hline & & & $\begin{array}{l}\text { Colonic fermentation } \\
\text { (limited evidence) }\end{array}$ & Indirect through cell signalling \\
\hline \multirow[t]{2}{*}{ Flavanoids } & Wheat, barley & Grain structure & Unknown & $\begin{array}{l}\text { Increase plasma uric acid levels which has reducing and free } \\
\text { radical scavenging activities }\end{array}$ \\
\hline & & & & Improve glutathione radical scavenging system \\
\hline Selenium & $\begin{array}{l}\text { Wheat, barley, } \\
\text { oats, rye }\end{array}$ & $\begin{array}{l}\text { Not relevant as } \\
\text { readily available }\end{array}$ & $\begin{array}{l}\text { Not relevant as } \\
\text { readily available }\end{array}$ & $\begin{array}{l}\text { A cofactor for glutathione peroxidase, an enzyme that } \\
\text { quenches reactive oxygen species }\end{array}$ \\
\hline
\end{tabular}


b. Cereal bioprocessing for improving phytochemical bioavailability

Cereal bioprocessing is receiving increasing attention as a technique for purportedly improving the bioavailability of bound phytochemicals in grains. This technique utilises hydrolytic enzymes or enzyme cocktails to selectively release phytochemicals from the bran layer. However, there is very little evidence that cereal bioprocessing actually improves phytochemical bioavailability in humans. Recently Anson and colleagues [112] developed a bioprocessing technique whereby wheat bran undergoes a yeast fermentation and enzyme treatment procedure. When this wheat bran was incorporated into a wholemeal bread and consumed by volunteers the plasma concentrations of ferulic, vanillic and sinapic acids, and 3,4-dimethoxybenzoic acid were 2- to 3-fold higher than in the control bread [45]. Ferulic acid in particular increased in plasma to a maximal level of $2.5 \mu \mathrm{mol} / \mathrm{L}$, which is considerably higher than baseline levels reported previously (5 to $30 \mathrm{nmol}$ ) [113]. The relevance of these changes in circulating phytochemical levels to metabolic health impact has yet to be demonstrated.

c. Phytochemical bioavailability in the large intestine: role of the microbiota

Microbial fermentation of cereal grains has the potential to increase the bioavailability of phytochemicals bound to the fibre matrix [114-117]. For instance, microbial esterases hydrolyse conjugated phenolic acids, such as those from wheat bran $[118,119]$, potentially improving their absorption.[120]. In addition, ferulic acid from wheat bran has been shown to increase plasma antioxidant activity more effectively than pure ferulic acid in rats [121]. This highlights the important function cereals may have in delivering ferulic acid to the large bowel whereby enzymes from the microbiota cause the slow release of ferulic acid up to $24 \mathrm{~h}$ after its consumption. However, in humans there is limited evidence that large bowel fermentation contributes significantly to plasma phytochemical levels in the systemic circulation. A study by Kern et al. [113] showed that the absorption of wheat bran phenolics was limited essentially to the postprandial period. Plasma phenolics and metabolites of ferulic acid (hydroxycinnamic and diferulic acids) were at baseline levels 6 to $24 \mathrm{~h}$ after wheat bran consumption, suggesting that the microbial fermentation of the ingested wheat bran did not contribute to the systemic phenolic level. In addition, the authors also showed that diferulic acids (formed by microbial esterase digestion of ferulic acid) or their reduced dimers (formed by colonic microbiota hydrogenation reactions of diferulic acids) could not be detected in plasma or urine samples. In a study by Anson et al. [45] whole wheat bread increased plasma concentrations of two metabolites of ferulic acid (3-hydroxyphenylpropionic acid and phenylpropionic acid) 9 to $24 \mathrm{~h}$ after consumption by healthy volunteers. It is unlikely that these metabolites exert any biological affects systemically as the maximal plasma concentrations reached were only in the nanomolar range $(100 \mathrm{nmol} / \mathrm{L}$ and $350 \mathrm{nmol} / \mathrm{L}$ respectively). The evidence suggests that the colonic microbiota contribute little to systemic levels of phenolic metabolites.

\section{Impact of wholegrain phytochemicals on metabolic health}

Various blood and urine biomarkers are routinely used to determine the metabolic health benefits of wholegrain phytochemicals. For instance, plasma and urine levels of oxidised lipids provide an indirect measure of the capacity of cereal phytochemicals to protect circulating lipids from damage by reactive oxygen species. In addition, circulating levels of C-reactive protein and pro-inflammatory cytokines are indicative of low grade systemic inflammation, a hallmark of many metabolic diseases.

a. Oxidised lipids

There is some evidence supporting a role for wholegrain consumption in reducing oxidised lipids in plasma or urine. Kim et al. [122] showed that a mixture of brown and black rice when consumed for 6 wk by healthy adults reduced plasma thiobarbituric acid reactive substance (TBARS) levels. Jang et al. [19] also showed a reduction in oxidised plasma malondialdehyde (MDA) and urine 8-epi-prostaglandin F2 $\alpha$ when subjects with coronary heart disease consumed a wholegrain powder mix $(70 \mathrm{~g} / \mathrm{d})$ for $4 \mathrm{mo}$. Two other studies of shorter duration (2 and $6 \mathrm{wk}$ ) in which refined grain foods were replaced with wholegrain foods (7 to 8 servings/d) did not show any improvements in urinary levels of oxidised lipids.[123,124] LDL susceptibility to oxidation was also similar when healthy subjects consumed $250 \mathrm{~g}$ of rye or wheat bran bakery products for 6 weeks [103]. It is not clear from these later studies [103,123,124] whether the lack of an effect was due to the shorter duration of the interventions, differences in wholegrain type or differences in the type of biological fluid analysed (urine was analysed rather than plasma).

b. Antioxidant defence The most promising evidence for wholegrain-rich diets improving blood-based antioxidant defence is through modulation of the glutathione radical scavenging system. This system utilises glutathione 
peroxidase to metabolise hydrogen peroxide to water by using reduced glutathione as a hydrogen donor [125]. The capacity for reduced glutathione to quench free radicals can be impaired if oxidised glutathione is not recycled back to glutathione by glutathione reductase, or if glutathione peroxidase activity is reduced [125]. An increase in reduced glutathione (21\%) occurred 15 min after healthy subjects consumed an oat extract containing $1 \mathrm{~g}$ avenanthramide-enriched mixture and remained elevated (by up to 14\%) for $10 \mathrm{~h}$ [126], a dose which far exceeds a level that could be achieved by consumption of wholegrain oats.. Alternatively, wholegrain dietary intervention studies showed that plasma glutathione peroxidase activity increased by $15 \%$ when subjects consumed brown and black rice for $6 \mathrm{wk}$ [122] but decreased by 35\% when subjects consumed a phytochemical-rich diet containing wholegrains for $4 \mathrm{wk}$ [127]. These studies suggest that the type of wholegrain and duration of consumption is important in regulating glutathione enzyme status or redox state. A possible mechanism explaining the effect of wholegrains on glutathione balance comes from in vitro evidence that flavonoids alter the expression of genes responsible for the synthesis and regulation of glutathione (Table 2) $[128,129]$. There is further evidence from a dietary intervention study in humans that selenium improves glutathione peroxidase activity [130]. Subjects consuming brown or wholemeal bread made from wheat containing high levels of selenium increased whole blood glutathione peroxidase levels by $10 \%$ [131]. As most people in European countries have plasma selenium levels below the recommended level [132], wholegrain cereals with high selenium concentrations may offer an opportunity to improve glutathione status. Alternatively, Fardet [48] recently proposed that wholegrain wheat may increase glutathione levels through the supply of the sulfur amino acids methionine and cystine, which are precursors of glutathione. However, these amino acids are present in wholegrain wheat at low levels ( $0.5 \%$ of protein) [133], thus other dietary sources of sulphur amino acids such as egg and meat would presumably have a greater influence on circulating selenium levels. There is limited evidence for whole grain-rich diets affecting copper-zinc superoxide dismutase (SOD), uric acid and tocopherol levels in the blood. Plasma SOD levels were unaffected in a study where subjects consumed black rice for 6 mo [134]. In contrast, another study showed that erythrocyte SOD levels were reduced when healthy adults consumed a phytochemical-rich diet containing wholegrains for 4 wk [127]. Plasma uric acid levels were increased (by 9\%) in subjects who had consumed bread (200 g/d) made from inulin, linseed and soya fibre for $5 \mathrm{wk}$ [135]. These findings are biologically significant in that uric acid accounts for up to $90 \%$ of plasma total antioxidant capacity [136]. Furthermore, high levels of flavanoids in some wholegrains are responsible for increasing plasma total antioxidant capacity as a result of stimulating uric acid levels rather than through the direct actions of flavonoids [136]. However, further research is required that investigates the impact of flavanoid-rich cereal consumption on uric acid levels and antioxidant status in healthy people as well as those with metabolic syndrome and T2D. Plasma $\alpha$-tocopherol concentrations barely increase after consumption of wholegrains suggesting that this compound is of limited importance for the prevention of T2D [135], In addition, $\alpha$-tocopherol contributes less than $2 \%$ of the antioxidant capacity of plasma [137], and a wholegrain-rich diet cannot provide the level of Vitamin E necessary to reduce oxidative stress in people with T2D (> $200 \mathrm{mg} / \mathrm{d}$ )

[138] Furthermore, a review of human clinical trials concluded that vitamin E, and other common antioxidants, were not useful for managing diabetic complications [139].

c. Antioxidant capacity of blood Most dietary intervention studies on wholegrains have used the ferric reducing antioxidant potential (FRAP) assay to determine plasma total antioxidant capacity. In two studies by the same group, meals consisting of approximately $100 \mathrm{~g}$ of wheat bran were fed to subjects and the postprandial change in plasma antioxidant status measured $[98,140]$. Both studies showed an increase but in the study by Beattie et al. [140] the magnitude of the response was only $4 \%$ (an increase of approximately $50 \mu \mathrm{mol}$ of FRAP/L from a baseline of 1,204 $\pm 57.5 \mu \mathrm{mol}$ of FRAP/L). It is not known whether this change is sufficient to protect against oxidative stress, a hallmark of metabolic syndrome and T2DM, and many other chronic diseases. In a study of longer duration (5 wk) fasted plasma FRAP levels did not change when subjects consumed bread (200 g/d) made with inulin, linseed and soya fibre, which had a $50 \%$ higher $\alpha$-tocopherol content than the control German wheat-rye bread [135]. Although these studies show a somewhat promising result for wheat bran in improving plasma antioxidant capacity, the FRAP assay has some limitations. For instance, it does not account for the antioxidant capacity provided by blood proteins (as they too are extracted in sample preparation) and the assay is 
based on the reduction of iron which is considered too slow a measure of antioxidant potential $[137,141]$. Alternative antioxidant capacity assays, such as the one for plasma total antioxidant capacity (TAC), have been used to show an increase in plasma antioxidant capacity in subjects with coronary heart disease who consumed black rice for 6 mo [134]. Other total antioxidant capacity assays, such as the Oxygen Radical Absorbance Capacity (ORAC) and Trolox Equivalent Antioxidant Capacity (TEAC), may be useful for evaluating radical scavenging, however they are not suitable for assessing lipid peroxidation inhibition [142]. Thus future studies should deploy a combination of different antioxidant capacity assays and the results interpreted in the context of changes in plasma lipid and protein oxidative stress biomarkers and clinical outcomes.

d. Anti-inflammatory actions

There is growing evidence supporting a reduction in pro-inflammatory markers in people consuming higher levels of wholegrains and/or cereal fibre. For instance, cereal fibre intakes (> $8.8 \mathrm{~g} / \mathrm{d}$ ), but not total fibre, were associated with significantly lower plasma cytokine levels in healthy adults [143]. Intervention trials provide evidence that plasma cytokines or C-reactive protein were reduced after consumption of bakery products containing rye bran [144], bread made from whole wheat with bioprocessed bran [45] or a black rice pigment fraction [134].

The fibre component of wholegrains is often associated with having favourable effects on proinflammatory markers including C-reactive protein and interleukin-6 $[145,146]$. In particular, the fermentation of cereal fibre in the large bowel produces short chain fatty acids (SCFA) that bind to G-protein coupled receptors, inhibiting transcription factor $\mathrm{Nf}_{\mathrm{K}} \beta$ and thereby increasing the threshold for an inflammatory response in the colonic mucosa [147]. The anti-inflammatory actions of SCFA may extend beyond the large bowel as these bacterial metabolites are readily absorbed by colonocytes [148]. However, SCFA concentrations in the systemic circulation are low $(<0.2 \mathrm{mM})$ as most SCFA absorbed from the lumen of the gut are metabolised extensively by the gut mucosa and the liver. Furthermore, consumption of fermentable dietary fibres produces only a modest rise in plasma SCFA levels [149]. Whether these modest levels of circulating SCFA are sufficient to prevent or attenuate the elevated inflammatory status of individuals with diabetes and related disorders is yet to be established and deserves further investigation.
Dietary fibre may help prevent chronic inflammation by also reducing circulating levels of lipoplysaccharides (LPS), which are known to contribute to the development of obesity-related inflammatory liver diseases [150-152]. The consumption of prebiotics has been shown to restrict the translocation of LPS from the large bowel of mice fed a high fat diet, resulting in reduced markers of inflammation in adipose tissue [153]. However, the relevance of these findings for humans is not yet clear.

\section{Conclusions}

Evidence from postprandial and medium-term intake studies suggest that the phytochemical component of cereals provides limited benefit for preventing oxidative stress and development of T2D. Wholegrain consumption may increase postprandial plasma phenolic levels but the response is modest and transient. Whether this effect is sufficient to bolster antioxidant defences and improve health outcomes has not been established. Although there is growing interest in the colonic microbiota and bio-processing for increasing phytochemical bioavailability the improvements so far are small and have not improved markers of clinical relevance for reducing risk of T2D. Future dietary intervention studies seeking to establish a direct role of phytochemicals in mediating the metabolic health benefits of wholegrains, and their potential for mitigating disease progression, should consider using varieties that deliver the highest possible levels of bioavailable phytochemicals in the context of whole foods and diets. Both postprandial and prolonged responses in systemic phytochemical concentrations and markers of inflammation and oxidative stress should be monitored and along with changes related to health outcomes in healthy individuals as well as those with metabolic disease.

\section{Abbreviations \\ FAE: Ferulic acid equivalent; FRAP: Ferric reducing antioxidant potential; LPS: Lipopolysaccharide; MDA: Malondialdehyde; ORAC: Oxygen Radical Absorbance Capacity; SCFA: Short chain fatty acid; SOD: Superoxide dismutase; TAC: Total antioxidant capacity; TBARS: Thiobarbituric acid reactive substance; TEAC: Trolox Equivalent Antioxidant Capacity; T2D: Type-2 diabetes Mellitus.}

Competing interests

There are no conflicts of interest.

\section{Authors' contributions}

DPB and ARB participated in the acquisition, analysis and interpretation of data, and drafting of the manuscript. Both authors read and approved the final manuscript.

Received: 27 February 2013 Accepted: 24 April 2013

Published: 16 May 2013 


\section{References}

1. Shaw JE, Sicree RA, Zimmet PZ: Global estimates of the prevalence of diabetes for 2010 and 2030. Diabetes Res Clin Pract 2010, 87:4-14.

2. Whiting DR, Guariguata L, Weil C, Shaw J: IDF diabetes atlas: global estimates of the prevalence of diabetes for 2011 and 2030. Diabetes Res Clin Pract 2011, 94:311-321.

3. Walgate R: Diabetes research for developing countries. N Biotechnol 2008, 25:111-116.

4. Misra A, Singhal N, Khurana L: Obesity, the metabolic syndrome, and type 2 diabetes in developing countries: role of dietary fats and oils. J Am Coll Nutr 2010, 29:289S-301S.

5. Fitzgerald MA, Rahman S, Resurreccion AP, Concepcion J, Daygon VD, Dipti SS, Kabir KA, Klingner B, Morell M, Bird A: Identification of a major genetic determinant of glycaemic index in rice. Rice 2011, 4:66-74.

6. Knowler WC, Barrett-Connor E, Fowler SE, Hamman RF, Lachin JM, Walker EA, Nathan DM: Reduction in the incidence of type 2 diabetes with lifestyle intervention or metformin. N Engl J Med 2002, 346:393-403.

7. Fung TT, Hu FB, Pereira MA, Liu S, Stampfer MJ, Colditz GA, Willett WC: Whole-grain intake and the risk of type 2 diabetes: a prospective study in men. Am J Clin Nutr 2002, 76:535-540.

8. Hodge AM, English DR, O'Dea K, Giles GG: Dietary patterns and diabetes incidence in the Melbourne Collaborative Cohort Study. Am J Epidemiol 2007, 165:603-610.

9. Brunner EJ, Mosdol A, Witte DR, Martikainen P, Stafford M, Shipley MJ, Marmot MG: Dietary patterns and 15-y risks of major coronary events, diabetes, and mortality. Am J Clin Nutr 2008, 87:1414-1421.

10. Nettleton JA, McKeown NM, Kanoni S, Lemaitre RN, Hivert MF, Ngwa J, van Rooij FJ, Sonestedt E, Wojczynski MK, Ye Z, et al: Interactions of dietary whole-grain intake with fasting glucose- and insulin-related genetic loci in individuals of European descent: a meta-analysis of 14 cohort studies. Diabetes Care 2010, 33:2684-2691.

11. Meyer KA, Kushi LH, Jacobs DR Jr, Slavin J, Sellers TA, Folsom AR Carbohydrates, dietary fiber, and incident type 2 diabetes in older women. Am J Clin Nutr 2000, 71:921-930.

12. McKeown NM, Meigs JB, Liu S, Wilson PW, Jacques PF: Whole-grain intake is favorably associated with metabolic risk factors for type 2 diabetes and cardiovascular disease in the Framingham Offspring Study. Am J Clin Nutr 2002, 76:390-398.

13. Pereira MA, Jacobs DR Jr, Pins JJ, Raatz SK, Gross MD, Slavin JL, Seaquist ER: Effect of whole grains on insulin sensitivity in overweight hyperinsulinemic adults. Am J Clin Nutr 2002, 75:848-855.

14. van Dam RM, Rimm EB, Willett WC, Stampfer MJ, Hu FB: Dietary patterns and risk for type 2 diabetes mellitus in U.S. men. Ann Intern Med 2002 136:201-209.

15. Murtaugh MA, Jacobs DR Jr, Jacob B, Steffen LM, Marquart L: Epidemiological support for the protection of whole grains against diabetes. Proc Nutr Soc 2003, 62:143-149.

16. Venn BJ, Mann J: Cereal grains, legumes and diabetes. Eur J Clin Nutr 2004, 58:1443-1461.

17. de Munter JS, Hu FB, Spiegelman D, Franz M, van Dam RM: Whole grain, bran, and germ intake and risk of type 2 diabetes: a prospective cohort study and systematic review. PLoS Med 2007, 4:e261.

18. Priebe MG, van Binsbergen JJ, de Vos R, Vonk RJ: Whole grain foods for the prevention of type 2 diabetes mellitus. Cochrane Database Syst Rev 2008, 23(1):CD006061.

19. Jang Y, Lee JH, Kim OY, Park HY, Lee SY: Consumption of whole grain and legume powder reduces insulin demand, lipid peroxidation, and plasma homocysteine concentrations in patients with coronary artery disease: randomized controlled clinical trial. Arterioscler Thromb Vasc Biol 2001, 21:2065-2071.

20. Lutsey PL, Jacobs DR Jr, Kori S, Mayer-Davis E, Shea S, Steffen LM, Szklo M, Tracy R: Whole grain intake and its cross-sectional association with obesity, insulin resistance, inflammation, diabetes and subclinical CVD: The MESA Study. Br J Nutr 2007, 98:397-405.

21. Rave K, Roggen K, Dellweg S, Heise T, Tom Dieck H: Improvement of insulin resistance after diet with a whole-grain based dietary product: results of a randomized, controlled cross-over study in obese subjects with elevated fasting blood glucose. Br J Nutr 2007, 98:929-936

22. Hallfrisch J, Fac N, Behall KM: Mechanisms of the effects of grains on insulin and glucose responses. J Am Coll Nutr 2000, 19:320S-325S.
23. Slavin J: Why whole grains are protective: biological mechanisms. Proc Nutr Soc 2003, 62:129-134.

24. Smith $C E$, Tucker KL: Health benefits of cereal fibre: a review of clinical trials. Nutr Res Rev 2011, 15:1-14.

25. Jonnalagadda SS, Harnack L, Liu RH, McKeown N, Seal C, Liu S, Fahey GC: Putting the whole grain puzzle together: health benefits associated with whole grains-summary of American Society for Nutrition 2010 Satellite Symposium. J Nutr 2011, 141:1011S-1022S.

26. Harris KA, Kris-Etherton PM: Effects of whole grains on coronary heart disease risk. Curr Atheroscler Rep 2010, 12:368-376.

27. Schulze MB, Schulz M, Heidemann C, Schienkiewitz A, Hoffmann K, Boeing $\mathrm{H}$ : Fiber and magnesium intake and incidence of type 2 diabetes: a prospective study and meta-analysis. Arch Intern Med 2007, 167:956-965.

28. Hu FB, Manson JE, Stampfer MJ, Colditz G, Liu S, Solomon CG, Willett WC: Diet, lifestyle, and the risk of type 2 diabetes mellitus in women. $N$ Engl J Med 2001, 345:790-797.

29. Brand-Miller J, McMillan-Price J, Steinbeck K, Caterson I: Dietary glycemic index: health implications. J Am Coll Nutr 2009, 28(Suppl):446S-449S.

30. Sluijs I, Beulens JW, der AD V, Spijkerman AM, Grobbee DE, Van der Schouw $Y T$ : Dietary intake of total, animal, and vegetable protein and risk of type 2 diabetes in the European Prospective Investigation into Cancer and Nutrition (EPIC)-NL study. Diabetes Care 2010, 33:43-48.

31. Barclay AW, Petocz P, McMillan-Price J, Flood VM, Prvan T, Mitchell P, BrandMiller JC: Glycemic index, glycemic load, and chronic disease risk-a meta-analysis of observational studies. Am J Clin Nutr 2008, 87:627-637.

32. Halton TL, Liu S, Manson JE, Hu FB: Low-carbohydrate-diet score and risk of type 2 diabetes in women. Am J Clin Nutr 2008, 87:339-346.

33. Livesey G, Taylor R, Hulshof T, Howlett J: Glycemic response and health-a systematic review and meta-analysis: relations between dietary glycemic properties and health outcomes. Am J Clin Nutr 2008, 87:258S-268S.

34. Brand-Miller J, McMillan-Price J, Steinbeck K, Caterson I: Carbohydrates-the good, the bad and the whole grain. Asia Pac J Clin Nutr 2008, 17(Suppl 1):16-19.

35. Okarter N, Liu RH: Health benefits of whole grain phytochemicals. Crit Rev Food Sci Nutr 2010, 50:193-208.

36. Ceriello A, Motz E: Is oxidative stress the pathogenic mechanism underlying insulin resistance, diabetes, and cardiovascular disease? The common soil hypothesis revisited. Arterioscler Thromb Vasc Biol 2004, 24:816-823.

37. Dandona P, Aljada A, Chaudhuri A, Mohanty P: Endothelial dysfunction, inflammation and diabetes. Rev Endocr Metab Disord 2004, 5:189-197.

38. Robertson RP: Chronic oxidative stress as a central mechanism for glucose toxicity in pancreatic islet beta cells in diabetes. $J$ Biol Chem 2004, 279:42351-42354.

39. Brownlee M: Biochemistry and molecular cell biology of diabetic complications. Nature 2001, 414:813-820.

40. Niedowicz DM, Daleke DL: The role of oxidative stress in diabetic complications. Cell Biochem Biophys 2005, 43:289-330.

41. Cardona F, Tunez I, Tasset I, Montilla P, Collantes E, Tinahones FJ: Fat overload aggravates oxidative stress in patients with the metabolic syndrome. Eur J Clin Invest 2008, 38:510-515.

42. Pizent A, Pavlovic M, Jurasovic J, Dodig S, Pasalic D, Mujagic R: Antioxidants, trace elements and metabolic syndrome in elderly subjects. J Nutr Health Aging 2010, 14:866-871.

43. Levitan EB, Cook NR, Stampfer MJ, Ridker PM, Rexrode KM, Buring JE, Manson JE, Liu S: Dietary glycemic index, dietary glycemic load, blood lipids, and C-reactive protein. Metabolism 2008, 57:437-443.

44. Guo W, Kong E, Meydani M: Dietary polyphenols, inflammation, and cancer. Nutr Cancer 2009, 61:807-810

45. Anson NM, Aura AM, Selinheimo E, Mattila I, Poutanen K, van den Berg R, Havenaar R, Bast A, Haenen GR: Bioprocessing of wheat bran in whole wheat bread increases the bioavailability of phenolic acids in men and exerts antiinflammatory effects ex vivo. J Nutr 2011, 141:137-143.

46. Hanhineva K, Torronen R, Bondia-Pons I, Pekkinen J, Kolehmainen M, Mykkanen H, Poutanen K: Impact of dietary polyphenols on carbohydrate metabolism. Int J Mol Sci 2010, 11:1365-1402

47. Salas-Salvado J, Martinez-Gonzalez MA, Bullo M, Ros E: The role of diet in the prevention of type 2 diabetes. Nutr Metab Cardiovasc Dis 2011, 21(Suppl 2):B32-48.

48. Fardet A: New hypotheses for the health-protective mechanisms of whole-grain cereals: what is beyond fibre? Nutr Res Rev 2010, 23:65-134. 
49. Adom KK, Sorrells ME, Liu RH: Phytochemicals and antioxidant activity of milled fractions of different wheat varieties. J Agric Food Chem 2005, 53:2297-2306

50. Slavin JL, Jacobs D, Marquart L: Grain processing and nutrition. Crit Rev Biotechnol 2001, 21:49-66.

51. Bryngelsson S, Dimberg LH, Kamal-Eldin A: Effects of commercial processing on levels of antioxidants in oats (Avena sativa L.). J Agric Food Chem 2002, 50:1890-1896.

52. Qiu Y, Liu Q, Beta T: Antioxidant activity of commercial wild rice and identification of flavonoid compounds in active fractions. J Agric Food Chem 2009, 57:7543-7551.

53. Xu SY, Cheng HJ, Guo YY, Ding SR: Amino acid contents of barley grains in relation to cultivars and cultivation conditions. Zhejiang Agricultural Science 1988:254-259.

54. Fickler J, Fontaine J, Heimbeck W: The amino acid composition of feedstuffs. Ridgefield Park, NJ; 2001.

55. Lee TT, Wang MM, Hou RC, Chen LJ, Su RC, Wang CS, Tzen JT: Enhanced methionine and cysteine levels in transgenic rice seeds by the accumulation of sesame 2S albumin. Biosci Biotechnol Biochem 2003, 67:1699-1705.

56. Council NAoS-NR: Joint United States-Canadian tables of Feed Composition. 2nd edition. Washington, D.C; 1964

57. Gibson C, Lyons G, Choi B, Park S, Stewart D: Selenium enriched barley. Biofortification to improve human health. Hobart, Australia: 12th Australian Barley Technical Symposium; 2005.

58. Williams PN, Lombi E, Sun GX, Scheckel K, Zhu YG, Feng X, Zhu J, Carey AM, Adomako E, Lawgali $Y$, et al: Selenium characterization in the global rice supply chain. Environ Sci Technol 2009, 43:6024-6030.

59. Eurola M, Hietaniemi V, Kontturi M, Tuuri H, Kangas A, Niskanen M, Saastamoinen M: Selium content of Finnish oats in 1997-1999: effect of cultivars and cultivation techniques. Ag Food Sci 2004, 13:46-53.

60. Fardet A, Llorach R, Orsoni A, Martin JF, Pujos-Guillot E, Lapierre C, Scalbert A: Metabolomics provide new insight on the metabolism of dietary phytochemicals in rats. J Nutr 2008, 138:1282-1287.

61. Ward JL, Poutanen K, Gebruers K, Piironen V, Lampi AM, Nystrom L, Andersson AA, Aman P, Boros D, Rakszegi M, et al: The HEALTHGRAIN Cereal Diversity Screen: concept, results, and prospects. J Agric Food Chem 2008, 56:9699-9709.

62. Bruce SJ, Guy PA, Rezzi S, Ross AB: Quantitative measurement of betaine and free choline in plasma, cereals and cereal products by isotope dilution LC-MS/MS. J Agric Food Chem 2010, 58:2055-2061.

63. Britz SJ, Prasad PV, Moreau RA, Allen LH Jr, Kremer DF, Boote KJ: Influence of growth temperature on the amounts of tocopherols, tocotrienols, and gamma-oryzanol in brown rice. J Agric Food Chem 2007, 55:7559-7565.

64. Nystrom L, Lampi A-M, Andersson AAM, Kamal-Eldin A, Gebruers K, Courtin CM, Delcour JA, Li L, Ward JL, Fras A, et al: Phytochemicals and Dietary Fiber Components in Rye Varieties in the HEALTHGRAIN Diversity Screen. J Agric Food Chem 2008, 56:9758-9766.

65. Barnes PJ: Cereal tocopherols. Amsterdam: Elsevier; 1983.

66. Lasztity R, Berndorfer-Kraszner E, Huszar M: On the presence and distribution of some bioactive agents in oat varieties. New York: Academic Press; 1980.

67. Ehrenbergerova J, Belcrediova N, Pryma J, Vaculova K, Newman CW: Effect of cultivar, year grown, and cropping system on the content of tocopherols and tocotrienols in grains of hulled and hulless barley. Plant Foods Hum Nutr 2006, 61:145-150.

68. Shewry PR, Piironen V, Lampi A-M, Nystrom L, Li L, Rakszegi M, Fras A, Boros D, Gebruers K, Courtin CM, et al: Phytochemical and Fiber Components in Oat Varieties in the HEALTHGRAIN Diversity Screen. J Agric Food Chem 2008, 56:9777-9784.

69. Zilic S, Sukalovic VH, Dodig D, Maksimovic V, Maksimovic M, Basic Z: Antioxidant activity of small grain cereals caused by phenolics and lipid soluble antioxidants. J Cereal Sci 2011, 54:417-424.

70. Evans LE, Dedio W, Hill RD: Variability in the alkylresorcinol content of rye grains. Can J Plant Sci 1973, 53:485-488.

71. Dimberg LH, Molteberg EL, Solheim R, Frølich W: Variation in Oat Groats Due to Variety, Storage and Heat Treatment. I: Phenolic Compounds. J Cereal Sci 1996, 24:263-272.

72. Emmons CL DMP: Antioxidant activity and phenolic content of oat as affected by cultivar and location. Crop Sci 2001, 41:1676-1681.

73. de Zwart FJ, Slow S, Payne RJ, Lever M, George PM, Gerrard JA, Chambers ST: Glycine betaine and glycine betaine analogues in common foods. Food Chem 2003, 83:197-204.
74. Andersson AAM, Lampi A-M, Nystrom L, Piironen V, Li L, Ward JL, Gebruers K, Courtin CM, Delcour JA, Boros D, et al: Phytochemical and Dietary Fiber Components in Barley Varieties in the HEALTHGRAIN Diversity Screen. J Agric Food Chem 2008, 56:9767-9776.

75. Baublis AJ, Lu C, Clydesdale FM, Decker EA: Potential of wheat-based breakfast cereals as a source of dietary antioxidants. J Am Coll Nutr 2000, 19:308S-311S

76. Mattila P, Pihlava JM, Hellstrom J: Contents of phenolic acids, alkyl- and alkenylresorcinols, and avenanthramides in commercial grain products. J Agric Food Chem 2005, 53:8290-8295.

77. Parikka K, Rowland IR, Welch RW, Wahala K: In vitro antioxidant activity and antigenotoxicity of 5-n-alkylresorcinols. J Agric Food Chem 2006, 54:1646-1650

78. Adom KK, Sorrells ME, Liu RH: Phytochemical profiles and antioxidant activity of wheat varieties. J Agric Food Chem 2003, 51:7825-7834.

79. Lampi A-M, Nurmi T, Ollilainen V, Piironen V: Tocopherols and Tocotrienols in Wheat Genotypes in the HEALTHGRAIN Diversity Screen. J Agric Food Chem 2008, 56:9716-9721.

80. Davis KR, Peters $L$, LeTourneau D: Variability of the vitamin content of wheat. Cereal Foods World 1984, 29:364-370.

81. Clarke B, Liang R, Morell MK, Bird AR, Jenkins CL, Li Z: Gene expression in a starch synthase lla mutant of barley: changes in the level of gene transcription and grain composition. Funct Integr Genomics 2008, 8:211-221.

82. Bird AR, Vuaran MS, King RA, Noakes M, Keogh J, Morell MK, Topping DL: Wholegrain foods made from a novel high-amylose barley variety (Himalaya 292) improve indices of bowel health in human subjects. $\mathrm{Br} \mathrm{J}$ Nutr 2008, 99:1032-1040.

83. King RA, Noakes M, Bird AR, Morell MK, Topping DL: An extruded cereal made from a high amylose barley cultivar has a low glycemic index and lower plasma insulin response than one made from a standard barley. J Cereal Sci 2008, 48:526-530.

84. Ross AB, Aman P, Andersson R, Kamal-Eldin A: Chromatographic analysis of alkylresorcinols and their metabolites. J Chromatogr A 2004, 1054:157-164.

85. Peterson DM, Qureshi AA: Genotype and environment effects on tocols of barley and oats. Cereal Chem 1993, 70:157-162.

86. Peterson DM: Oat Antioxidants. J Cereal Sci 2001, 33:115-129.

87. Bergman CJ, Xu Z: Genotype and environment effects on tocopherol, tocotrienol, and ç-oryzanol contents of southern U.S. rice. Cereal Chem 2003, 80:446-449.

88. Miller A, Engel $\mathrm{KH}$ : Content of gamma-oryzanol and composition of steryl ferulates in brown rice (Oryza sativa L.) of European origin. J Agric Food Chem 2006, 54:8127-8133.

89. Moore J, Hao Z, Zhou K, Luther M, Costa J, Yu LL: Carotenoid, tocopherol, phenolic acid, and antioxidant properties of Maryland-grown soft wheat. J Agric Food Chem 2005, 53:6649-6657.

90. Lampi AM, Nurmi T, Piironen V: Effects of the environment and genotype on tocopherols and tocotrienols in wheat in the HEALTHGRAIN diversity screen. J Agric Food Chem 2010, 58:9306-9313

91. Fernandez-Orozco R, Li L, Harflett C, Shewry PR, Ward JL: Effects of Environment and Genotype on Phenolic Acids in Wheat in the HEALTHGRAIN Diversity Screen. J Agric Food Chem 2010, 58:9341-9352.

92. Li L, Shewry PR, Ward JL: Phenolic Acids in Wheat Varieties in the HEALTHGRAIN Diversity Screen. J Agric Food Chem 2008, 56:9732-9739.

93. Heaney RP: Factors influencing the measurement of bioavailability, taking calcium as a model. J Nutr 2001, 131:1344S-1348S.

94. Riedl J, Linseisen J, Hoffmann J, Wolfram G: Some Dietary Fibers Reduce the Absorption of Carotenoids in Women. J Nutr 1999, 129:2170-2176.

95. Fenech M, Noakes M, Clifton P, Topping D: Aleurone Flour Is a Rich Source of Bioavailable Folate in Humans. J Nutr 1999, 129:1114-1119.

96. Scholz S, Williamson G: Interactions affecting the Bioavailability of dietary polyphenols in vivo. Int J Vitam Nutr Res 2007, 77:224-235.

97. Manach C, Scalbert A, Morand C, Rémésy C, Jiménez L: Polyphenols: food sources and bioavailability. Am J Clin Nutr 2004, 79:727-747.

98. Price R, Welch R, Lee-Manion A, Bradbury I, Strain JJ: Total phenolics and antioxidant potential in plasma and urine of humans after consumption of wheat bran. Cereal Chem 2008, 85:152-157.

99. Ross AB, Kamal-Eldin A, Lundin EA, Zhang JX, Hallmans G, Aman P: Cereal alkylresorcinols are absorbed by humans. J Nutr 2003, 133:2222-2224.

100. Linko-Parvinen AM, Landberg R, Tikkanen MJ, Adlercreutz H, Penalvo JL: Alkylresorcinols from whole-grain wheat and rye are transported in human plasma lipoproteins. J Nutr 2007, 137:1137-1142. 
101. Landberg R, Linko AM, Kamal-Eldin A, Vessby B, Adlercreutz H, Aman P: Human plasma kinetics and relative bioavailability of alkylresorcinols after intake of rye bran. J Nutr 2006, 136:2760-2765.

102. Kamal-Eldin A, Poruru A, Eliasson AC, Aman P: Alkylresorcinols as antioxidants: hydrogen donation and peroxyl radical-scavenging effects. J Sci Food Agric 2001, 81:353-356.

103. Harder $H$, Tetens I, Let MB, Meyer AS: Rye bran bread intake elevates urinary excretion of ferulic acid in humans, but does not affect the susceptibility of LDL to oxidation ex vivo. Eur J Nutr 2004, 43:230-236.

104. Craig SA: Betaine in human nutrition. Am J Clin Nutr 2004, 80:539-549.

105. Price RK, Keaveney EM, Hamill LL, Wallace JM, Ward M, Ueland PM, McNulty H, Strain JJ, Parker MJ, Welch RW: Consumption of wheat aleurone-rich foods increases fasting plasma betaine and modestly decreases fasting homocysteine and LDL-cholesterol in adults. J Nutr 2010, 140:2153-2157.

106. Likes R, Madl RL, Zeisel SH, Craig SA: The betaine and choline content of a whole wheat flour compared to other mill streams. J Cereal Sci 2007, 46:93-95.

107. Hallberg L, Hulthen L: Prediction of dietary iron absorption: an algorithm for calculating absorption and bioavailability of dietary iron. Am J Clin Nutr 2000, 71:1147-1160

108. Serafini M, Laranjinha JA, Almeida LM, Maiani G: Inhibition of human LDL lipid peroxidation by phenol-rich beverages and their impact on plasma total antioxidant capacity in humans. J Nutr Biochem 2000, 11:585-590.

109. van der Burg-Koorevaar MC, Miret S, Duchateau GS: Effect of milk and brewing method on black tea catechin bioaccessibility. J Agric Food Chem 2011, 59:7752-7758.

110. Reddy VC, Vidya Sagar GV, Sreeramulu D, Venu L, Raghunath M: Addition of milk does not alter the antioxidant activity of black tea. Ann Nutr Metab 2005, 49:189-195.

111. van het Hof KH, Kivits GA, Weststrate JA, Tijburg LB: Bioavailability of catechins from tea: the effect of milk. Eur J Clin Nutr 1998, 52:356-359.

112. Anson NM, Selinheimo E, Havenaar R, Aura AM, Mattila I, Lehtinen P, Bast A, Poutanen K, Haenen GR: Bioprocessing of wheat bran improves in vitro bioaccessibility and colonic metabolism of phenolic compounds. J Agric Food Chem 2009, 57:6148-6155.

113. Kern SM, Bennett RN, Mellon FA, Kroon PA, Garcia-Conesa MT: Absorption of hydroxycinnamates in humans after high-bran cereal consumption. J Agric Food Chem 2003, 51:6050-6055.

114. Rice-Evans C: Flavonoid antioxidants. Curr Med Chem 2001, 8:797-807.

115. Scalbert A, Morand C, Manach C, Remesy C: Absorption and metabolism of polyphenols in the gut and impact on health. Biomed Pharmacother 2002, 56:276-282.

116. Selma MV, Espin JC, Tomas-Barberan FA: Interaction between Phenolics and Gut Microbiota: Role in Human Health. J Agric Food Chem 2009, 57:6485-6501

117. Hervert-Hernandez D, Goni I: Dietary Polyphenols and Human Gut Microbiota: a Review. Food Reviews International 2011, 27:154-169.

118. Andreasen MF, Kroon PA, Williamson G, Garcia-Conesa MT: Intestinal release and uptake of phenolic antioxidant diferulic acids. Free Radic Biol Med 2001, 31:304-314.

119. Andreasen MF, Kroon PA, Williamson G, Garcia-Conesa MT: Esterase activity able to hydrolyze dietary antioxidant hydroxycinnamates is distributed along the intestine of mammals. J Agric Food Chem 2001, 49:5679-5684.

120. Kroon PA, Faulds CB, Ryden P, Robertson JA, Williamson G: Release of covalently bound ferulic acid from fiber in the human colon. J Agric Food Chem 1997, 45:661-667.

121. Rondini L, Peyrat-Maillard M-N, Marsset-Baglieri A, Fromentin G, Durand P, Tomé D, Prost M, Berset C: Bound Ferulic Acid from Bran Is More Bioavailable than the Free Compound in Rat. J Agric Food Chem 2004, 52:4338-4343.

122. Kim SH, Lee SS, Kim JY, Kim JH, Lee Da H: Meal replacement with mixed rice is more effective than white rice in weight control, while improving antioxidant enzyme activity in obese women. Nutrition research (New York, NY) 2008, 28:66-71.

123. Enright $L$, Slavin J: No effect of 14 day consumption of whole grain diet compared to refined grain diet on antioxidant measures in healthy, young subjects: a pilot study. Nutr J 2010, 9:12.

124. Andersson A, Tengblad S, Karlstrom B, Kamal-Eldin A, Landberg R, Basu S, Aman P, Vessby B: Whole-grain foods do not affect insulin sensitivity or markers of lipid peroxidation and inflammation in healthy, moderately overweight subjects. J Nutr 2007, 137:1401-1407.
125. Valko M, Leibfritz D, Moncol J, Cronin MTD, Mazur M, Telser J: Free radicals and antioxidants in normal physiological functions and human disease. Int J Biochem Cell Biol 2007, 39:44-84.

126. Chen CY, Milbury PE, Collins FW, Blumberg JB: Avenanthramides are bioavailable and have antioxidant activity in humans after acute consumption of an enriched mixture from oats. J Nutr 2007 137:1375-1382.

127. Bruce B, Spiller GA, Klevay LM, Gallagher SK: A diet high in whole and unrefined foods favorably alters lipids, antioxidant defenses, and colon function. J Am Coll Nutr 2000, 19:61-67.

128. Myhrstad MC, Carlsen H, Nordstrom O, Blomhoff R, Moskaug JO: Flavonoids increase the intracellular glutathione level by transactivation of the gamma-glutamylcysteine synthetase catalytical subunit promoter. Free Radic Biol Med 2002, 32:386-393.

129. Moskaug JO, Carlsen H, Myhrstad MC, Blomhoff R: Polyphenols and glutathione synthesis regulation. Am J Clin Nutr 2005, 81:277S-283S.

130. Thomson CD, Ong LK, Robinson MF: Effects of supplementation with high-selenium wheat bread on selenium, glutathione peroxidase and related enzymes in blood components of New Zealand residents. Am J Clin Nutr 1985, 41:1015-1022.

131. Barclay MNI, Macpherson A: Selenium content of wheat for bread making in Scotland and the relationship between glutathione-peroxidase levels in whole-blood and bread consumption. Br J Nutr 1992, 68:261-270.

132. Fairweather-Tait SJ, Bao Y, Broadley MR, Collings R, Ford D, Hesketh JE, Hurst R: Selenium in human health and disease. Antioxid Redox Signal 2011, 14:1337-1383.

133. del Molino IMM, Rojo B, Martínez-Carrasco R, Pérez P: Varietal differences in amino acid composition of wheat (Triticum aestivum L) grain. J Sci Food Agric, 48:177-188.

134. Wang Q, Han P, Zhang M, Xia M, Zhu H, Ma J, Hou M, Tang Z, Ling W: Supplementation of black rice pigment fraction improves antioxidant and anti-inflammatory status in patients with coronary heart disease. Asia Pac J Clin Nutr 2007, 16(Suppl 1):295-301.

135. Seidel C, Boehm V, Vogelsang H, Wagner A, Persin C, Glei M, Pool-Zobel BL, Jahreis $\mathrm{G}$ : Influence of prebiotics and antioxidants in bread on the immune system, antioxidative status and antioxidative capacity in male smokers and non-smokers. Br J Nutr 2007, 97:349-356.

136. Lotito SB, Frei B: Consumption of flavonoid-rich foods and increased plasma antioxidant capacity in humans: Cause, consequence, or epiphenomenon? Free Radic Biol Med 2006, 41:1727-1746.

137. Erel O: A novel automated direct measurement method for total antioxidant capacity using a new generation, more stable ABTS radical cation. Clin Biochem 2004, 37:277-285.

138. Bartlett HE, Eperjesi F: Nutritional supplementation for type 2 diabetes: a systematic review. Ophthalmic Physiol Opt 2008, 28:503-523.

139. Golbidi S, Ebadi SA, Laher I: Antioxidants in the treatment of diabetes. Curr Diabetes Rev 2011, 7:106-125.

140. Beattie R, Lee A, Strain J: Evaluation of the in vivo antioxidant activity of wheat bran in human subjects. Proc Nutr Soc 2003, 62:17A.

141. Ou B, Huang D, Hampsch-Woodill M, Flanagan JA, Deemer EK: Analysis of antioxidant activities of common vegetables employing oxygen radical absorbance capacity (ORAC) and ferric reducing antioxidant power (FRAP) assays: a comparative study. J Agric Food Chem 2002, 50:3122-3128

142. Niki E: Assessment of antioxidant capacity in vitro and in vivo. Free Radic Biol Med 2010, 49:503-515.

143. Chuang SC, Vermeulen R, Sharabiani MT, Sacerdote C, Fatemeh SH, Berrino F, Krogh V, Palli D, Panico S, Tumino R, et al: The intake of grain fibers modulates cytokine levels in blood. Biomarkers 2011, 16:504-510.

144. de Mello VD, Schwab U, Kolehmainen M, Koenig W, Siloaho M, Poutanen K, Mykkanen $\mathrm{H}$, Uusitupa M: A diet high in fatty fish, bilberries and wholegrain products improves markers of endothelial function and inflammation in individuals with impaired glucose metabolism in a randomised controlled trial: the Sysdimet study. Diabetologia 2011, 54:2755-2767.

145. Oliveira A, Rodriguez-Artalejo F, Lopes C: The association of fruits, vegetables, antioxidant vitamins and fibre intake with high-sensitivity C-reactive protein: sex and body mass index interactions. Eur J Clin Nutr 2009, 63:1345-1352

146. Herder C, Peltonen M, Koenig W, Sutfels K, Lindstrom J, Martin S, llanne-Parikka $P$, Eriksson JG, Aunola S, Keinanen-Kiukaanniemi S, et al: Anti-inflammatory 
effect of lifestyle changes in the Finnish Diabetes Prevention Study. Diabetologia 2009, 52:433-442.

147. Al-Lahham SH, Peppelenbosch MP, Roelofsen H, Vonk RJ, Venema K: Biological effects of propionic acid in humans; metabolism, potential applications and underlying mechanisms. Biochim Biophys Acta 1801, 2010:1175-1183.

148. Roelofsen H, Priebe MG, Vonk RJ: The interaction of short-chain fatty acids with adipose tissue: relevance for prevention of type 2 diabetes. Benef Microbes 2010, 1:433-437.

149. Verbeke K, Ferchaud-Roucher V, Preston T, Small AC, Henckaerts L, Krempf $M$, Wang H, Vonk RJ, Priebe MG: Influence of the type of indigestible carbohydrate on plasma and urine short-chain fatty acid profiles in healthy human volunteers. Eur I Clin Nutr 2010, 64:678-684.

150. Adachi Y, Moore LE, Bradford BU, Gao W, Thurman RG: Antibiotics prevent liver injury in rats following long-term exposure to ethanol. Gastroenterology 1995, 108:218-224.

151. Lichtman SN, Keku J, Schwab JH, Sartor RB: Hepatic injury associated with small bowel bacterial overgrowth in rats is prevented by metronidazole and tetracycline. Gastroenterology 1991, 100:513-519.

152. Lichtman SN, Sartor RB, Keku J, Schwab JH: Hepatic inflammation in rats with experimental small intestinal bacterial overgrowth. Gastroenterology 1990, 98:414-423.

153. Cani PD, Possemiers S, Van de Wiele T, Guiot $Y$, Everard A, Rottier O, Geurts L, Naslain D, Neyrinck A, Lambert DM, et al: Changes in gut microbiota control inflammation in obese mice through a mechanism involving GLP-2-driven improvement of gut permeability. Gut 2009, 58:1091-1103.

doi:10.1186/1475-2891-12-62

Cite this article as: Belobrajdic and Bird: The potential role of phytochemicals in wholegrain cereals for the prevention of type-2 diabetes. Nutrition Journal 2013 12:62.

\section{Submit your next manuscript to BioMed Central and take full advantage of:}

- Convenient online submission

- Thorough peer review

- No space constraints or color figure charges

- Immediate publication on acceptance

- Inclusion in PubMed, CAS, Scopus and Google Scholar

- Research which is freely available for redistribution 